DEPÓSITO LEGAL ZU2020000153

Esta publicación científica en formato digital

es continuidad de la revista impresa

ISSN 0041-8811

E-ISSN 2665-0428

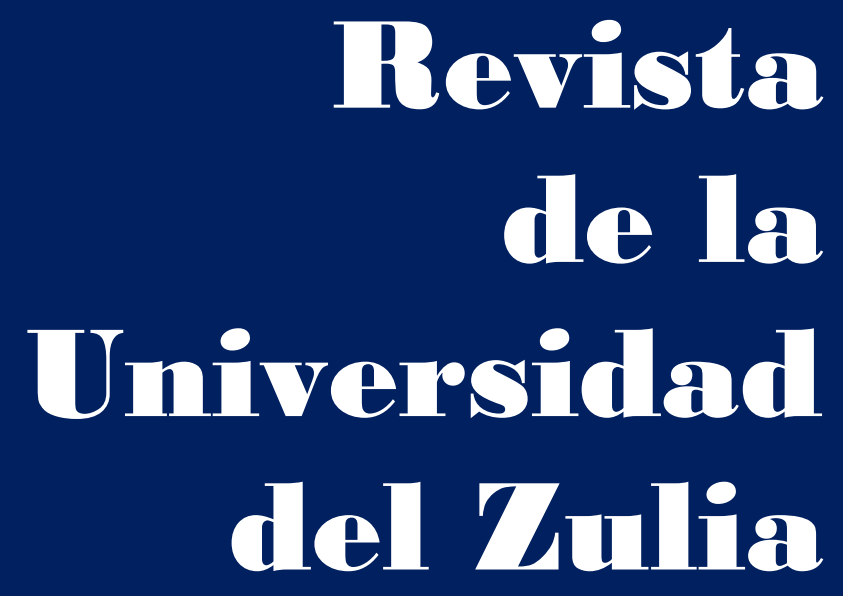

Fundada en 1947

por el Dr. Jesús Emrique Lossada

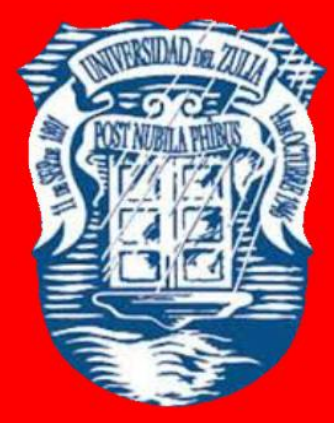

Ciencias

Sociales

y Arte

Año $12 \quad N^{\circ} 34$

Septiembre - Diciembre 2021

Tercera Época

Maracaibo-Veneruela 


\title{
Creativity and uncertainty tolerance as a resource for the psychological well-being of an individual
}

\author{
Yaroslava Z. Vasylkevych * \\ Polina O. Shalnieva** \\ Serhii M. Ryk \\ Halyna Ya. Zhyrska **** \\ Oksana M. Kikinezhdi *****
}

ABSTRACT

The objective of the work was to establish the features of creativity and uncertainty tolerance in people with different levels of psychological well-being. An empirical study of the level of manifestation of psychological well-being of the studied group and the relationship between the components of creativity and tolerance for uncertainty was conducted. The study was conducted using a set of psychological techniques aimed at determining the level of psychological well-being, uncertainty tolerance, creativity and their components. Qualitative methods of data processing are used. The study found that people with high levels of psychological well-being have close relationships between the indicators of the components of psychological well-being, creativity and uncertainty tolerance. Instead, these relationships are significantly fewer among people with low levels of psychological wellbeing.

KEYWORDS: creativity; tolerance; individual psychology; mental health.

* Associate Professor, Department of Psychology, Faculty of Historical and Socio-Psychological Education, Hryhorii Skovoroda University in Pereiaslav, Ukraine. ORCID: https://orcid.org/00000002-5946-3005. E-mail: vasylkevychslava@online.ua

** PhD Student, Department of Psychology, Faculty of Historical and Socio-Psychological Education, Hryhorii Skovoroda University in Pereiaslav, Ukraine. ORCID: https://orcid.org/0000-0002-67272321. E-mail: shalnevpolinka5@gmail.com

${ }^{* * *}$ Head of the Department of Philosophy, Faculty of Historical and Socio-Psychological Education, Hryhorii Skovoroda University in Pereiaslav, Ukraine. ORCID: https://orcid.org/0000-0002-11153876. E-mail: ryksm432@ukr.net

**** Associate Professor, Department of General Biology and Methodology of Natural Sciences Teaching, Faculty of Chemistry and Biology, Ternopil Volodymyr Hnatiuk National Pedagogical University, Ukraine. ORCID: https://orcid.org/0000-0002-7042-8956. E-mail: zhyrskahal5@gmail.com

***** Head of the Psychology Department, Faculty of Pedagogics and Psychology, Ternopil Volodymyr Hnatiuk National Pedagogical University, Ukraine. ORCID: https://orcid.org/00000002-9240-279X . E-mail: okkikinezhdi@gmail.com

Recibido: 10/06/2021

Aceptado: 29/07/2021 


\section{Creatividad y tolerancia a la incertidumbre como recurso para el bienestar psicológico de un individuo}

RESUMEN

El objetivo del trabajo fue establecer las características de la creatividad y la tolerancia a la incertidumbre en personas con diferentes niveles de bienestar psicológico. Se realizó un estudio empírico del nivel de manifestación del bienestar psicológico del grupo estudiado y la relación entre los componentes de la creatividad y la tolerancia a la incertidumbre. El estudio se llevó a cabo utilizando un conjunto de técnicas psicológicas destinadas a determinar el nivel de bienestar psicológico, la tolerancia a la incertidumbre, la creatividad y sus componentes. Se utilizan métodos cualitativos de procesamiento de datos. El estudio encontró que las personas con altos niveles de bienestar psicológico tienen relaciones cercanas entre los indicadores de los componentes de bienestar psicológico, creatividad y tolerancia a la incertidumbre. En cambio, estas relaciones son significativamente menores entre las personas con bajos niveles de bienestar psicológico.

PALABRAS CLAVE: creatividad; tolerancia; psicología individual; salud mental.

\section{Introduction}

Modern transformation processes place new demands on a person, which includes a quick search for new solutions in any situation. This leads to the active development of human resources, in particular - the creative potential of an individual. A person's ability to act creatively, in general, his/her inclination to creative activity is the basis of his/her development and successful activity. Modern educational paradigms change their vector from information-reproductive to personality-oriented and creativity-oriented, which also confirms the importance of the development of individual's creativity for himself/herself and for society as a whole.

The aim of the work is to clarify the features of the place of creativity and uncertainty tolerance in the structure of psychological well-being of an individual. The objectives of the work are: 1) analyse the latest research that examines the components of psychological wellbeing; 2) empirically establish the relationship between indicators of psychological wellbeing of an individual, his/her uncertainty tolerance and creativity.

Researcher and practitioner K. Dunker considered the problem of creativity from the standpoint of productive thinking, believing that problem situations of various kinds are the 


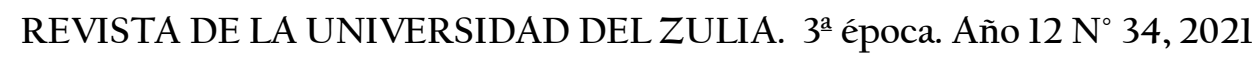
Yaroslava Z. Vasylkevych et al. /// Creativity and uncertainty tolerance as a resource... 585-603 DOI: http://dx.doi.org/10.46925//rdluz.34.32

main source of human creativity. He proposed an unconventional type of experimental study, which later received its own name - "Dunker's Candle Problem". This problem provides different options and solutions, has "several layers", and only one of these methods and options is adequate. It is necessary to understand the problem's internal structure in order to solve it, and only then start solving. Understanding the essence of the experiment leads to the solution of the problem. It can be achieved only provided the transformation of past personal experience, as well as the rejection of established stereotypes and schemes. There is a conflict between the set tasks and its conditions, which can be overcome only through understanding, insight (Preiss, 2019).

Kelly's cognitive theory of creativity considers creativity as an alternative to the banal. Without using the term "creativity", J. Kelly developed an original theory of creativity and creative personality, first describing alternative hypothetical thinking. For J. Kelly, a person is a researcher, a scholar who interacts effectively and creatively with the world, interpreting the world, processing information, predicting events. Human life is a study, a constant advancing of hypothesis of reality, through which a person tries to predict and control events. The picture of the world is hypothetical, and people advance hypotheses, test them, that is, perform the same mental actions as scholars in the course of scientific research. Life is a creative research process (Dimitrova-Burlaienko, 2017).

Wertheimer M. considered creativity from the standpoint of productive thinking, while he contrasted it with reproductive, which can only reproduce ready-made operations. Attention was focused on the desire to achieve a clear understanding of the situation or problem and led to the fact that it regroups the elements into some necessary whole, namely, a "good" gestalt. Creating a "good" structure is through recentring, which means the transition from one-sided understanding to centring, which is determined by the objective side of the situation and moves the centre of the proposed situation from one object to another (Karwowski \& Kaufman, 2017; Kaufman \& Sternberg, 2019).

A special contribution to the understanding of the essence of creativity and creative development was made by the founders of psychoanalysis. Classical psychoanalysis ( $Z$. Freud, K. Jung, A. Adler, etc.) considers creativity as the formation of creative energy and the projection of motivation for creative activity (Preiss, 2019; Ryff, 1995). Freud believed that the result of the sublimation of sexual instincts is creative activity, with the transfer of energy 
REVISTA DE LA UNIVERSIDAD DEL ZULIA. 3é época. Año $12 \mathrm{~N}^{\circ}$ 34, 2021

Yaroslava Z. Vasylkevych et al. /// Creativity and uncertainty tolerance as a resource... 585-603 DOI: http://dx.doi.org/10.46925//rdluz.34.32

from more undifferentiated, primitive and undesirable impulses to more differentiated, higher, spiritual, cultural. He says that in Western culture and science, sexual instincts are becoming the main impetus for great achievements, which is how the mechanism of creative energy formation works (Kwan et al., 2018).

In scientific researchers (Andronnikova \& Veterok, 2016; Dimitrova-Burlaienko, 2017), creativity is considered from various aspects:

creativity as the ability to quickly assimilate, process and use new information in various non-standard ways. The importance of inductive thinking and some features of perception in the creative achievements of the individual. Creative decisions more often arise during relaxation, distraction, and not when a person is focused on solving a problem;

- " "non-standard thinking";

- $\quad$ three components that most affect the creativity of individual thinking, in particular: motivation to work; ability in a certain (specific) field; creative processes;

- $\quad$ feature of intelligence or the highest level of intellectual activity of thinking;

- $\quad$ creativity as a basis for the development of professionalism. Creativity in work is the ability to creatively consider the initial data, generate ideas that go beyond standards and traditional schemes of thinking, quickly solve problem situations;

- creativity creates favourable conditions for the development of personality in general, promotes its self-revelation, self-fulfilment, self-sufficiency and tolerance;

several characteristics that form the image of a creative person, in particular: openness and ambiguity tolerance; no fear of the unknown;

creativity is integrative in nature, it is inextricably linked with the intellectual, emotional, reflective, volitional, motivational and activity spheres of personality;

consideration of creativity from the standpoint of problem situations, it is defined as the ability to solve many problems in ever-changing circumstances, the ability to make decisions in different situations, as well as a set of the following competencies: the ability to express one's needs and interests; ability to find other sources of information; ability to make decisions in different situations; ability to generate original ways to solve the problem (Muñoz, 2019);

a property or complex characteristics of personality;

type of intellectual ability; 
REVISTA DE LA UNIVERSIDAD DEL ZULIA. 3é época. Año $12 \mathrm{~N}^{\circ}$ 34, 2021 Yaroslava Z. Vasylkevych et al. /// Creativity and uncertainty tolerance as a resource... 585-603

- $\quad$ creative style of activity;

- $\quad$ the result of creative achievements of an individual.

The range of research by foreign scholars is quite wide: from the analysis of traits and motives of creative personalities, the so-called "I" in connection with creativity, to the study of creativity as self-actualisation and its relationship with psychiatry (Barron, 2009; Dimitrova-Burlaienko, 2017; Glăveanu, 2014).

Many researchers closely link creativity to the level of psychological well-being. In particular, it is believed that the revelation of a person's creative potential is an important foundation for his psychological well-being. Non-standard approaches allow a person to find solutions in stressful situations, which, in turn, has a positive effect on his/her resistance to negative factors and promotes mental health (Pakhol, 2017).

Creativity is also closely linked to uncertainty tolerance. Uncertainty can be a factor of stress, frustration, tension and lead to occupational health disorders. It is obvious that uncertainty tolerance and stress, as well as the ability to overcome them are extremely important factors that affect the psychological well-being of an individual (Norton, 2002; Apaza-Panca et al, 2021).

The analysis of the concept of uncertainty tolerance was the subject of research of many scholars. Psychologists study this concept using different conceptual approaches. The first approach was used in the works of E. Frenkel-Brunswick in 1948 and in 1949 in the study of authoritarian personality (Hitchcott et al., 2017; Rafferty et al., 2013). The second approach to the analysis of uncertainty tolerance is used in the theory of features in the concept of perception, which was proposed by S. Badner in 1962 (Barbot et al., 2019; Li, 2006; Paskov, 2017). The third approach treats uncertainty tolerance through models of rational decision-making and is based on the concept of "probability" (Hammond et al., 2017; Huang, 2006).

Based on the theoretical analysis of information, we assume that uncertainty tolerance and creativity are closely interrelated and are important structural components of the psychological well-being of an individual. This hypothesis became the basis for further empirical research.

\section{Methods}


REVISTA DE LA UNIVERSIDAD DEL ZULIA. 3época. Año $12 \mathrm{~N}^{\circ}$ 34, 2021 Yaroslava Z. Vasylkevych et al. /// Creativity and uncertainty tolerance as a resource... 585-603 DOI: http://dx.doi.org/10.46925//rdluz.34.32

Several stages of research were carried out to study the features of manifestations of creativity and uncertainty tolerance in the structure of psychological well-being. First, there was a review of scientific information and the formation of a theoretical model of research. The next step was the development of a research model, which involved the selection of a group of subjects and the selection of psychological techniques. Using a random sampling method, 300 people aged 22-33 were selected, who were registered at the State Employment Centre in Kyiv at the end of last year and are currently successfully employed.

The following questionnaires were selected for the study:

1) K. Riff's Scale of Psychological Well-being (adapted by T.D. Shevelenkova and P.P. Fesenko) is reflected in seven indicators: positive relationships with others, autonomy, environmental management, personal growth, life goal, self-acceptance and an integral indicator of psychological well-being (that is, its overall level).

2) Diener's Satisfaction with the Life Scale. Contains one scale, which indicates the level of psychological well-being in general.

3) Badner's Uncertainty Tolerance Questionnaire. It contains four scales - a general tolerance scale and scales that indicate its source - insolvability, novelty or complexity.

4) Diagnosis of personal creativity. Contains scales "creativity" (general scale), "propensity to risk" (defending one's own ideas despite the needs of others), "curiosity" (searching for new information and non-standard solutions), "complexity" (studying complex phenomena and processes), "imagination" (the level of development of the individual's imagination).

5) Johnson's Creativity Checklist adapted by Ye.Ye. Tunik is aimed at studying the general level of individual's creativity. The results of the answers for all questionnaires were calculated using mathematical formulas in Microsoft Excel, and qualitative analysis was performed using the Statistica package. The statistical methods of data processing involved one-way analysis of variance, which allows comparing the data in three or more subgroups, and Spearman's Rank Correlation Coefficient, which allows identifying relationships between two independent attributes in the same group.

\section{Results}

A quantitative analysis of the data was performed at the beginning of the empirical study. It was found that the subjects have characteristic features that involve the desire for 
REVISTA DE LA UNIVERSIDAD DEL ZULIA. 3época. Año $12 \mathrm{~N}^{\circ}$ 34, 2021 Yaroslava Z. Vasylkevych et al. /// Creativity and uncertainty tolerance as a resource... 585-603 DOI: http://dx.doi.org/10.46925//rdluz.34.32

change and willingness to find new solutions and overcome difficult situations. Accordingly, a high level of uncertainty tolerance was found in 55\% of respondents. Only $10 \%$ of respondents are not ready for the changing environmental conditions, they seek clarity and comprehensibility of the environment and the proposed solutions. It is also worth noting that $35 \%$ of respondents show an average level of uncertainty tolerance. That is, we can say that in general this study group is characterised by high levels of uncertainty tolerance.

Analysis of the sources of uncertainty suggests that in this study group, the highest indicators of tolerance are tolerance for the new situation. There are $60 \%$ of respondents who have a strong perception of changing living conditions and consider them an integral part of their lives. Almost half, $45 \%$ of respondents show an average level of tolerance for the complexity of the proposed situation, and for $37.5 \%$ the unsolvability of situations is partly a factor that can cause difficulties in everyday life (average level of uncertainty tolerance).

Diagnostics of the creativity level of the study group allowed obtaining the following results. According to the questionnaire for the diagnostics of personal creativity, it was found that a high creativity level is inherent in $52.5 \%$ of respondents, which is a very significant indicator. Only $12.5 \%$ of respondents have a low level of imagination, a tendency to take risks in certain situations and to understand complex problems.

It is interesting that the propensity to risk was found in $67.5 \%$ of subjects. More than half of the respondents tend to defend their ideas, not to be influenced by other people's opinions and set high goals. They strive to realise their plans, but at the same time they understand their mistakes and accept them.

Instead, the curiosity of the respondents is less developed. Only $22.5 \%$ of respondents have a high level of interest in the world, a tendency to seek new solutions and explore the surrounding reality. The majority of respondents (65\%) have an average level of this quality.

Knowledge of complex objects, solving atypical problems and perseverance in carrying out their own activities are typical for 30\% of respondents, the vast majority of respondents $(42.5 \%)$ have an average level of manifestation of this attribute.

On the other hand, imagination, as a tendency to invent original stories, thinking about new phenomena and objects, atypical perception of objects of the surrounding reality are not very typical of this study group, as $47.5 \%$ have low results on this scale, which is somewhat contradictory to other indicators of creativity. 
According to the Johnson's Creativity Checklist adapted by Ye.Ye. Tunik, there are 5 levels of creativity - very low, low, normal/medium, high and very high. It was found that the average level of creativity is inherent in $52.5 \%$ of respondents. Very low rates were not recorded in any of the respondents, low rates - in 17.5\% of respondents, high — in 25\% of respondents, and very high - in 5\% of respondents. As the results show, the subjects have an average level of propensity to find new solutions and atypical approaches to solving the situation. The subgroup with high creativity rates outnumbers people with a low level of creativity, which gives grounds to conclude about the medium-high level of creativity in this group.

The quantitative analysis of the data found that the overall level of psychological wellbeing of the subjects is moderate (low level was found in 35\% of people, medium level - in $40 \%$, high level - in 25\%). This suggests that the respondents evaluate their lives as moderately positive, they are not always satisfied with its quality and harmony and their selffulfilment. It is worth noting that a significant part of the subjects is completely dissatisfied with their lives, feel unhappy in it, experience imbalances in its various areas and subjectively experience the negativity of their functioning (Figure 1).

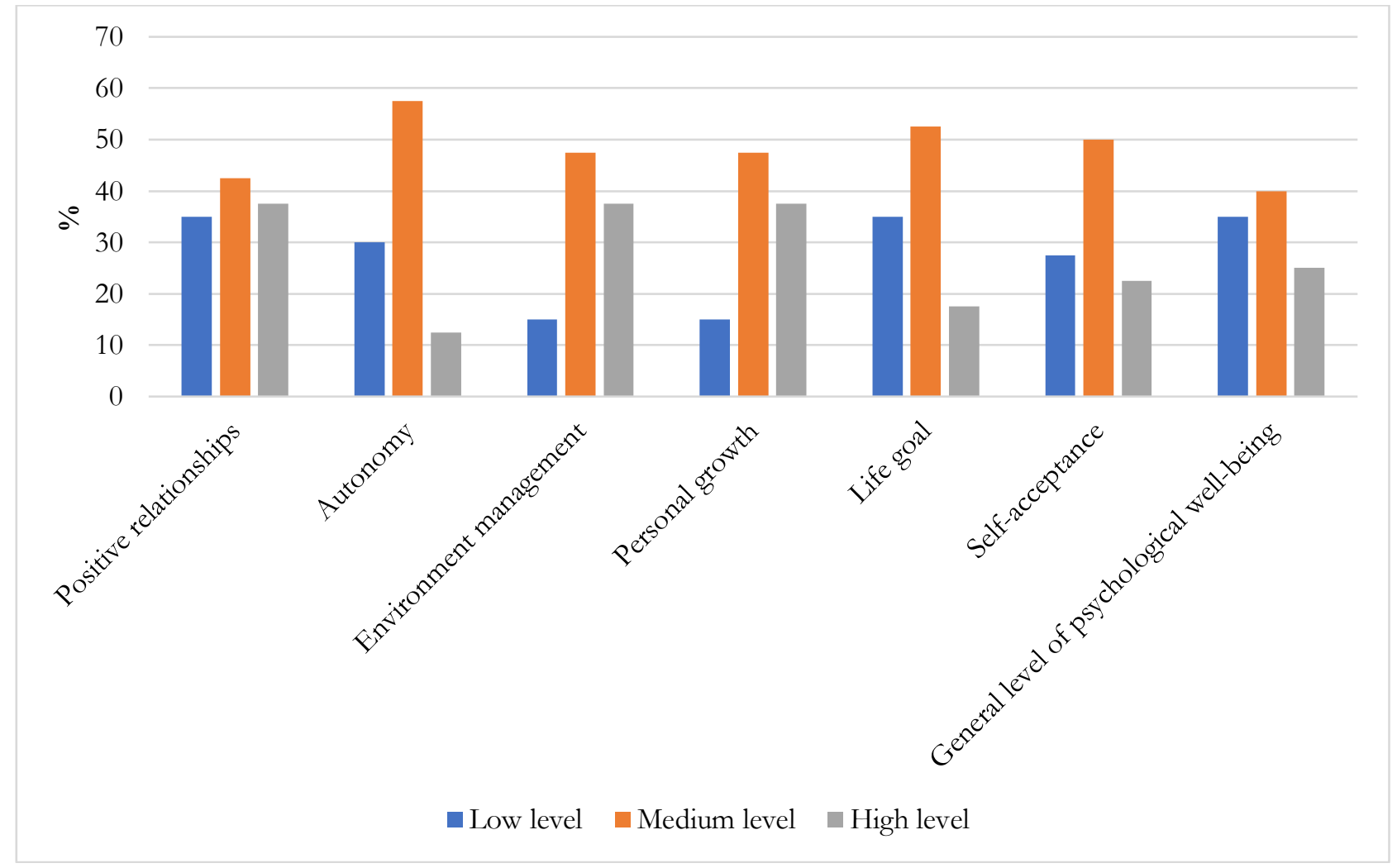

Figure 1. Distribution of indicators of psychological well-being of the respondents 
REVISTA DE LA UNIVERSIDAD DEL ZULIA. 3época. Año $12 \mathrm{~N}^{\circ}$ 34, 2021 Yaroslava Z. Vasylkevych et al. /// Creativity and uncertainty tolerance as a resource... 585-603 DOI: http://dx.doi.org/10.46925//rdluz.34.32

The analysis of separate components of psychological well-being allowed revealing the following features of group of subjects. The rate of positive relationships with others is expressed at an average level. They are quite good at building relationships with other people, take care of them, understand well that sometimes it is necessary to compromise and can empathise with others. Almost the same number of respondents have low and high scores on this scale - one part is mostly isolated from other people, they often experience frustration and cannot show openness in relationships; on the other hand, it is quite easy for the rest of the respondents to establish positive relationships with other people and take care of them.

According to the Autonomy scale, the results of the subjects were distributed as follows: $30 \%$ found low indicators on this scale, that is this part of the subjects is quite dependent on the opinions and actions of others, they are conformal and often rely on the opinion of another person; $42 \%$ of respondents are moderately able to resist influential environments and maintain their own positions; 37.5\% are very independent and autonomous, they strive to act only as they have decided, and rely only on their own criteria, not other people's ones, in assessing their own actions and judgments.

The data on the Environment Management scale are distributed differently. More than half of the respondents, which is $57.5 \%$, are able to organise their daily activities and adjust external influences for their own needs. Only $12 \%$ of respondents have high scores on this scale, that is they can effectively use a variety of opportunities to meet their own needs and achieve goals. Instead, 30\% of respondents have a low level of organisation of their activities, they believe that they are unable to adjust external influences for their own needs, feel unable to change adverse circumstances and believe that they cannot control anything in their lives.

Indicators on the Personal Growth scale are weakly manifested in only $15 \%$ of respondents, that is this subgroup has a low interest in life, they do not want to create new relationships or get new experiences from life, and feel that they can continue to grow and develop as individuals. The majority of respondents (47.5\%) quite successfully cope with these life challenges, have their own areas of interests and development. A great openness to new experiences, a significant desire for self-development and improvement of various areas of their lives is found in $37.5 \%$.

The indicators of the Life Goal scale are distributed as follows: $35 \%$ of the respondents showed low results on this scale, $52.5 \%$ - medium, and $17.5 \%$ - high. We can say that most 


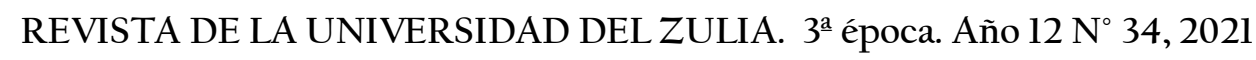
Yaroslava Z. Vasylkevych et al. /// Creativity and uncertainty tolerance as a resource... 585-603 DOI: http://dx.doi.org/10.46925//rdluz.34.32

of the subjects have a fairly clear vision of the development of their lives and understand their expectations of it, although sometimes they may experience existential difficulties. The subjects are also characterised by average indicators on the Self-Acceptance scale, which are recorded in $40 \%$ of respondents, that is this subgroup tends to fairly rationally assess their various sides. On the contrary, a significant part of the respondents (35\%) are too critical of themselves, they are disappointed with their achievements and criticise their own personal qualities. There were $25 \%$ of people diagnosed with a positive attitude towards themselves, they know how to use their negative experiences for learning, as well as understand and accept their negative qualities.

On the Diener's Satisfaction with the Life Scale, the following distribution of indicators is revealed: $2.5 \%$ of respondents rate the quality of their life very low, consider it disharmonious and not as they would like to see it. Another 25\% of respondents have a low level of indicators for this scale, that is we can conclude that a total of $27.5 \%$ of respondents are generally dissatisfied with their lives. More than half of respondents (52.5\%) feel happy in life at the average level. Another $17.5 \%$ are characterised by high rates on this scale, and $2.5 \%$ - very high rates, that is a total of $20 \%$ of respondents are completely satisfied with their lives and its various areas.

Quantitative calculation of data allowed dividing the subjects into three subgroups according to their level of psychological well-being (low $-n=50$, medium $-n=80$, high $\mathrm{n}=70$ ). Next, one-way analysis of variance revealed differences in scales such as the Dinner Life Satisfaction Scale, the general level of uncertainty tolerance, the problem unsolvability (component of uncertainty tolerance), the general level of creativity and imagination. Let us consider each of the results in detail.

It was found that life satisfaction is different for all three subgroups (Table l). Subjects with a high level of psychological well-being have, accordingly, a high level of satisfaction with their own life, its fullness and manifestations. People who have low indicators for mental health, a feeling of "emptiness" of life, lost days, do not have a specific goal where to go and do not feel general satisfaction with life.

Differences in the indicators of the integrated level of uncertainty tolerance were found only in subgroups with high and low levels of psychological well-being (Table 2). Subjects from the first subgroup are resistant to unusual and new situations, calmly perceive 
unexpected changes in circumstances and feel comfortable in such conditions. Instead, subjects with a low level of psychological well-being are very negative about unexpected changes in circumstances and find it difficult to adapt to them. Situations that do not have a specific and definite option of action, but are unpredictable and require a creative approach, can be critical for them.

Table 1 . The results of comparing life satisfaction

\begin{tabular}{llccc}
\hline \multirow{2}{*}{ Group } & $\{1\}$ & $\{2\}$ & $\{3\}$ \\
\cline { 3 - 5 } & & $M=16.0625$ & $M=28.7895$ & $M=42.121$ \\
\hline 1 & $\{1\}$ & & & \\
\hline 2 & $\{2\}$ & 0.788446 & & \\
\hline 3 & $\{3\}$ & 0.026658 & 0.189154 & \\
\hline
\end{tabular}

Table 2. The results of the comparison of uncertainty tolerance

\begin{tabular}{|c|c|c|c|c|}
\hline \multirow{2}{*}{\multicolumn{2}{|c|}{ Group }} & $\{1\}$ & $\{2\}$ & $\{3\}$ \\
\hline & & $M=16.0625$ & $M=28.7895$ & $M=42.121$ \\
\hline 1 & $\{1\}$ & & & \\
\hline 2 & $\{2\}$ & 0.046658 & & \\
\hline 3 & $\{3\}$ & & 0.189154 & \\
\hline
\end{tabular}

There were statistically significant differences between the indicators problem of unsolvability as a component of tolerance to uncertainty in subgroups with high and medium levels of psychological well-being. People with a high level of mental health have the ability to cope well with difficult problems. The subjects of this subgroup perceive those situations that other people can interpret as hopeless as those that can be overcome. In contrast to people with a high level of psychological well-being, people with a low level of this indicator are more negative about complex problems.

The general level of creativity also differs in the studied first and third subgroups (Table 3). People with a high level of psychological well-being tend to be creative in their daily lives. They experiment with new solutions and interesting ideas, consider them as a normal part of their lives and do not consider them too complicated and inaccessible. Instead, subjects with a low level of psychological well-being have difficulties using 


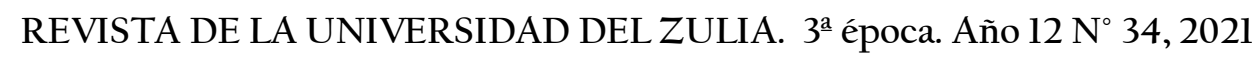

Yaroslava Z. Vasylkevych et al. /// Creativity and uncertainty tolerance as a resource... 585-603

DOI: http://dx.doi.org/10.46925//rdluz.34.32

unconventional approaches. These respondents prefer to use familiar and proven methods of solving situations and do not try to actively implement new ideas.

Table 3. The results of the comparison of creativity.

\begin{tabular}{llccc}
\hline \multirow{2}{*}{ Group } & & $\{1\}$ & $\{2\}$ & $\{3\}$ \\
\cline { 3 - 5 } & & $M=9.1250$ & $M=6.5789$ & $M=7.5279$ \\
\hline 1 & $\{1\}$ & & & \\
\hline 2 & $\{2\}$ & 0.448543 & & \\
\hline 3 & $\{3\}$ & 0.047358 & 0.281554 & \\
\hline
\end{tabular}

The last indicator which revealed differences in these subgroups was the imagination of the subjects. Its level also differs in the first and third subgroups, that is in subgroups with high to low levels of psychological well-being (Table 4).

Table 4 . The results of the comparison of imagination.

\begin{tabular}{llccc}
\hline \multirow{2}{*}{ Group } & \multicolumn{1}{c}{1} & $\{2\}$ & $\{3\}$ \\
\cline { 3 - 5 } \cline { 3 - 5 } & & $M=10.5625$ & $M=9.0000$ & $M=7.5455$ \\
\hline 2 & $\{1\}$ & & & \\
\hline 3 & $\{2\}$ & 0.234359 & & \\
\hline
\end{tabular}

The respondents who evaluate their own life as positive and full are more capable of creative imagination and the creation of new images. Instead, this is not typical for people from the third subgroup, and they have low imagination indicators.

Analysis of the correlation analysis data revealed such correlations in a subgroup of people with a high level of psychological well-being. Personal growth has a positive correlation with creativity $(0.523, \mathrm{p} \leq 0.001)$. The higher the creativity, the more the subjects seek to develop, be included in society and find new sources for their growth. Positive relationships with other people directly correlate with creativity $(0.463, p \leq 0.001)$. The higher the level of creativity, the more positive emotions prevail over negative ones in a personal communication. The respondents are prone to experience such emotions as joy, pleasure, fun in interpersonal interaction. Positive relationships with others also directly correlate with 


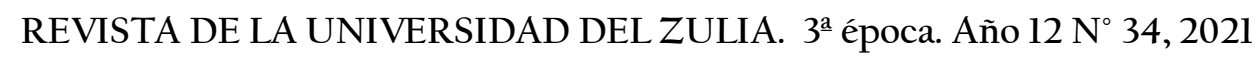

Yaroslava Z. Vasylkevych et al. /// Creativity and uncertainty tolerance as a resource... 585-603

DOI: http://dx.doi.org/10.46925//rdluz.34.32

the creativity level on the Johnson scale $(0.303, \mathrm{p} \leq 0.001)$. Thus, the higher the creativity, the more pronounced is the tendency to assess their interpersonal contacts positively.

Personal growth is also directly related to the performance indicators of the Johnson's Creativity Checklist $(0.352, \mathrm{p} \leq 0.001)$. The higher the level of creativity, the more the studied group has a sense of emotional satisfaction from their life and development and is confident in themselves and in their abilities.

The Life Goal indicators are positively correlated to creativity $(0.453, \mathrm{p} \leq 0.001)$. The more pronounced life goals and feelings of meaning in life, beliefs that give meaning to life, the higher the indicators of creativity.

It was also found that there is a correlation between uncertainty tolerance and the Autonomy scale $(0.521, \mathrm{p} \leq 0.001)$. This suggests that the ability to act effectively in unpredictable and unexpected situations allow generating the independence and autonomy of the respondent. A direct statistically significant relationship between the indicators of the Environment Management scale with uncertainty tolerance indicators. The level of uncertainty tolerance is related to the personal qualities of the respondent in having power and competence in the environment management and control over external activities. This may mean that such a person is able to act productively in an unfamiliar environment and will be able to take responsibility in the absence of information.

The correlation between personal growth and uncertainty tolerance was established (0.452, $\mathrm{p} \leq 0.001)$. This suggests that uncertainty tolerance can help increase a person's interest in life through the flexibility of his/her behaviour. Such a person will consider an unusual and ambiguous prospect as an opportunity to show his/her personal abilities.

The correlation between psychological well-being and uncertainty tolerance was established $(0.601, \mathrm{p} \leq 0.001)$ for the subgroup with medium indicators of psychological wellbeing. The increase in indicators of psychological well-being is associated with an increase in the resistance of the subjects to uncertain and unforeseen situations and their ability to cope with them. The overall indicator of uncertainty tolerance directly correlates with the creativity level $(0.492, \mathrm{p} \leq 0.001)$ in this subgroup. There were no statistically significant correlations between creativity and uncertainty tolerance with such scales of psychological well-being as Autonomy, Environmental Management, Positive Relationships with Others, Life Goal and Self-Acceptance in the group of subjects with a medium level of psychological 
REVISTA DE LA UNIVERSIDAD DEL ZULIA. 3é época. Año $12 \mathrm{~N}^{\circ}$ 34, 2021

Yaroslava Z. Vasylkevych et al. /// Creativity and uncertainty tolerance as a resource... 585-603

DOI: http://dx.doi.org/10.46925//rdluz.34.32

well-being. It can be stated that for this subgroup a statistically significant correlation for these scales is not established.

The results of correlation analysis of the components of psychological well-being, creativity and uncertainty tolerance allow us to consider the features of the relationship of these indicators in a subgroup of people with low indicators of psychological well-being. It is important to note that the indicator of life satisfaction in this subgroup and the creativity level by two methods have a negative correlation coefficient $(r=-0.249$ and $r=-0.341, p$ $<0.001)$. This indicates that the subjects have a high indicators for solving problem situations in non-standard ways and think original, assess their condition rather as unfavourable. They may experience emotional discomfort, anxiety about their personal qualities, lack of interest in the events of their own lives, have fewer goals and intentions. It can be assumed that the self-esteem of such persons and their emotional state is mostly unstable.

The general indicators of creativity in both methods negatively correlated with the ability to build positive relationships with others, which indicates the difficulty of this subgroup of people in building close trusting relationships ( $\mathrm{r}=-0.342$ and $\mathrm{r}=-0.431, \mathrm{p}<0.001$ ). Creativity, which is manifested in everyday life, cannot always be understood and accepted in the immediate environment, which can significantly complicate communication.

The group of people with a low level of psychological well-being is characterised by the correlation between such a component of psychological well-being as Personal Growth and the originality of the answers ( $\mathrm{r}=0.424 ; \mathrm{p}<0.001)$. Personal growth and life goals, as well as the ability to create conditions that are comfortable to meet personal needs and achieve goals set, inversely correlate with the originality of thinking.

\section{Discussion}

Uncertainty tolerance as a psychological characteristic of a person is important in maintaining internal balance, in combating stereotypes and prejudices, as well as in the stability of professional efficiency (Bilopolyi \& Lazarenko, 2020). Within the life and rhythm of the metropolis, uncertainty in various life situations can cause a person to feel complete rejection and confusion (DeRoma et al., 2003). This can be experienced by a person as a concern that someone may ignore, someone will try to suppress, and this can result in such manifestations as avoidance, frustration and refusal to implement plans (Hammond et al., 2017; Lubart, 2010). 
REVISTA DE LA UNIVERSIDAD DEL ZULIA. 3é época. Año $12 \mathrm{~N}^{\circ}$ 34, 2021 Yaroslava Z. Vasylkevych et al. /// Creativity and uncertainty tolerance as a resource... 585-603 DOI: http://dx.doi.org/10.46925//rdluz.34.32

Factors of uncertainty of internal environment directly correlate with the psychological well-being of an individual (Archangelidi \& Mentzakis, 2017; Cachioni et al., 2017; Diener et al., 1999; Gilligan et al., 2017). Psychological well-being, above all, is presented as a holistic, subjective experience, as an integral mental phenomenon, a set of experiences that reflects the successful functioning of an individual in a society, with a favourable emotional background, whose psyche and body are in a functional state, as well as a positive view of oneself and the world around (Archangelidi \& Mentzakis, 2017; Bradburn, 1965).

It is not possible to fix psychological well-being at a certain level. Psychological wellbeing is a constant balancing act on the border of the desired and the real, a harmonious process of uniting parts into a whole in the context of society with the goal of finding a stable balance (Chapman \& Dammeyer, 2017; Wilson et al., 2020).

It should also be noted that quite often creativity is a factor that has a positive effect on well-being. The basis of psychological well-being is the principle of activity, flexibility of thinking of the subject. The concept of "flexibility of thinking" of the subject refers to his/her readiness for new experiences, in self-fulfilment and self-development, which helps to eliminate self-doubt, thereby relieving internal tension, emotional discomfort, which is also characteristic of a person with a high level of tolerance, who is able to accept the novelty and uncertainty of situations and able to act productively in them (González-Hernández et al., 2019; Wilson et al., 2020).

There is an influence of environmental factors on the relationship between talent, creativity and psychological well-being. The studies noted the influence of others on creativity (Bluth et al., 2017; Chapman \& Dammeyer, 2017; Chiu et al., 2018).

Based on data on the role of creativity in solving not only educational but also everyday problems, researchers suggest that the psychological well-being of people with different levels of creativity will also have different levels (Evans, 2016; Gilligan et al., 2017).

It was found that subjects with different levels of psychological well-being have differences in such indicators as the general level of uncertainty tolerance, problem unsolvability (component of uncertainty tolerance), the general level of creativity, imagination and satisfaction with life.

Numerous correlations between creativity, uncertainty tolerance and components of psychological well-being were identified in a group of subjects with a high level of 


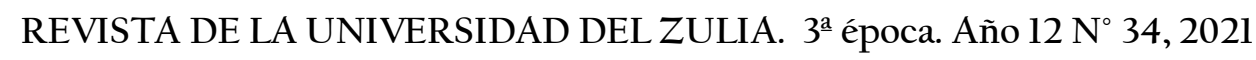
Yaroslava Z. Vasylkevych et al. /// Creativity and uncertainty tolerance as a resource... 585-603 DOI: http://dx.doi.org/10.46925//rdluz.34.32

psychological well-being. For example, the relationship between personal growth and uncertainty tolerance was identified. This suggests that uncertainty tolerance can help increase a person's interest in life through the flexibility of his/her behaviour. He/she will consider an unusual and ambiguous prospect as an opportunity to show his/her personal abilities. Improving one's capabilities and, consequently, uncertainty tolerance can have a positive effect on personal growth and human development.

Other correlations were also established - Personal Growth has a positive correlation with creativity; Positive Relationships with other people directly correlate with creativity; Life Goal indicators positively correlate with creativity. It was also found that there is a link between uncertainty tolerance and the Autonomy scale.

For the subgroup with average psychological well-being, the correlation between psychological well-being and uncertainty tolerance was established. In this subgroup, the overall indicator of uncertainty tolerance directly correlated with the level of creativity. This subgroup is characterised by the least number of correlations between the studied indicators.

The following correlations are characteristic of a subgroup with low indicators of psychological well-being: the indicator of life satisfaction in this subgroup and the level of their creativity by two methods have a negative correlation coefficient; general indicators of creativity by both methods negatively correlated with the ability to build positive relationships with others, which indicates the difficulty of this subgroup of people in building close trusting relationships. A group of people with a low level of psychological well-being is also characterised by the relationship between such a component of psychological well-being as Personal Growth and the originality of the answers.

\section{Conclusions}

Psychological well-being is an important structural entity that directly correlates with and has a significant impact on a person's mental health. Maintaining a sufficiently high level of psychological well-being ensures the normal functioning of a person, his/her feeling of happiness and subjective satisfaction with life. The level of psychological well-being affects all areas of human life - from relationships with others and success at work to inner integrity and harmony.

However, there are a significant number of factors that have a significant impact on the formation and functioning of the psychological well-being of an individual. In this article, 
REVISTA DE LA UNIVERSIDAD DEL ZULIA. 3é época. Año $12 \mathrm{~N}^{\circ}$ 34, 2021

Yaroslava Z. Vasylkevych et al. /// Creativity and uncertainty tolerance as a resource... 585-603

DOI: http://dx.doi.org/10.46925//rdluz.34.32

uncertainty tolerance and creativity were considered as important mental formations related to human mental health. The influence of these components on the psychological well-being of an individual is theoretically analysed and substantiated. It was empirically proved that individuals with different levels of psychological well-being have different indicators of uncertainty tolerance, creativity and their components. Numerous correlations were found between the indicators of these scales. We consider clarifying the place of creativity and uncertainty tolerance in the structure of psychological well-being, in particular in different age groups, and comparing the results to be the prospect for further research.

\section{References}

Andronnikova, O. O., \& Veterok, E. V. (2016). Psychological well-being and health as the actual needs of modern people in the context of reduction of victimization. Bulletin of Kemerovo State University. Psychology, 1(65), 72-76. https://cyberleninka.ru/article/n/psihologicheskoeblagopoluchie-i-zdorovie-kak-aktualnaya-potrebnost-sovremennogo-cheloveka-v-ramkahdeviktimizatsii/viewer

Apaza-Panca, C. M., Maquera-Luque, P. J., Huanca-Frías, J. O., Supo-Quispe, L. A., TávaraRamos, A. P., Dextre-Martínez, W. R., \& Saldaña-Acosta, O. A. (2021). Factores psicosociales en estudiantes universitarios de Loreto, Ancash, Moquegua y Puno durante el confinamiento por el Covid-19, Perú. Cuestiones Políticas, 39(68), 51-69. https:/produccioncientificaluz.org/index.php/cuestiones/article/view/35395

Archangelidi, O., \& Mentzakis, E. (2017). Body-weight and psychological well-being in the UK general population. Public Health (Oxf), 5, 1-8. https://doi.org/10.1093/pubmed/fdx054

Barbot, B., Hass, R. W., \& Reiter-Palmon, R. (2019). Creativity assessment in psychological research: (Re) setting the standards. Psychology of Aesthetics, Creativity, and the Arts, 13(2), 233240. https://doi.org/10.1037/aca0000233

Barron, F. (2009). Creative person and creative process. NY: Holt, Rhinehart \& Winston.

Bilopolyi, V. V., \& Lazarenko, V. I. (2020). Psychological readiness for personal changes and tolerance for the uncertainty of the modern world of students of construction free economic education (SHEI PSACEA). Bulletin of Prydniprovs'ka State Academy of Civil Engineering and Architecture, 2, 263-264. https://doi.org/10.30838/J.BPSACEA.2312.280420.16.617

Bluth, K., Campo, R. A., Futch, W. S., \& Gaylord, S. A. (2017). Age and gender differences in the associations of self-compassion and emotional well-being in a large adolescent sample. Journal of Youth and Adolescence, 46, 840-853. https://doi.org/10.1007/s10964-016-0567-2

Bradburn, N. M. (1965). Reports on happiness. A pilot study of Behaviour related to mental health. Chicago, USA: Aldine Publishing Company. 
REVISTA DE LA UNIVERSIDAD DEL ZULIA. 3época. Año $12 \mathrm{~N}^{\circ}$ 34, 2021

Yaroslava Z. Vasylkevych et al. /// Creativity and uncertainty tolerance as a resource... 585-603

DOI: http://dx.doi.org/10.46925//rdluz.34.32

Cachioni, M., Delfino, L. L., Yassuda, M. S., Batistoni, S., de Melo, R. C., \& da Costa Domingues, M. (2017). Subjective and psychological well-being among elderly participants of a University of the Third Age. Revista Brasileira de Geriatria e Gerontologia, 20(3), 340-35l. https://doi.org/10.1590/1981-22562017020.160179

Chapman, M., \& Dammeyer, J. (2017). The significance of deaf identity for psychological well-being. The Journal of Deaf Studies and Deaf Education, 22(2), 187-194. https://doi.org/10.1093/deafed/enw073

Chiu, C.-Y., Lun, V. M., \& Bond, M. H. (2018). Engaging in creative work: The influences of personal value, autonomy at work, and national socialization for self-directedness in 50 nations. Journal of Cross-Cultural Psychology, 49, 239-260. https://doi.org/10.1177/0022022116651336

DeRoma, V. M., Martin, K. M., \& Kessler, M. L. (2003). The Relationship between tolerance for ambiguity and need for course structure. Journal of Instructional Psychology, 30(2), 104-109.

Diener, E., Suh, E. M., Lucas, R. E., \& Smith, H. L. (1999). Subjective well-being: Three decades of progress. Psychological Bulletin, 125(2), 276-302. https://doi.org/10.1037/00332909.125.2.276

Dimitrova-Burlaienko, S. D. (2017). The genesis of the concept of "creative competence" in the context of psychological and pedagogical research. Zbirnyk naukovykh prats "Pedahohika ta psykholohiia", 58, 35-42.

Evans, G. W. (2016). Childhood poverty and adult psychological well-being. Proceeding of the National Academy of Sciences of the United States of America, 113(52). 14949-14952. https://doi.org/10.1073/pnas.1604756114

Gilligan, M., Suitor, J. J., Nam, S., Routh, B., Rurka, M., \& Con, G. (2017). Family networks and psychological well-being in midlife. Social Sciences. 6(3), 94-99. https://doi.org/10.3390/socsci6030094

Glăveanu, V. (2014). The psychology of creativity: A critical reading. Creativity Theories Research - Applications, 1, 10-29. https://doi.org/10.15290/ctra.2014.01.01.02

González-Hernández, J., Gómez-López, M., Pérez-Turpin, J., Muñoz-Villena, A., \& AndreuCabrera, E. (2019). Perfectly active teenagers. When does physical exercise help psychological well-being in adolescents? International Journal of Environmental Research and Public Health, 16(22), 4525. https://doi.org/10.3390/ijerphl6224525

Hammond, J., Hancock, J., Martin, M., Jameson, S., \& Mellor, D. (2017). Development of a new scale to measure ambiguity tolerance in veterinary students. Journal of Veterinary Medical Education, 44(1), 38-49. https://doi.org/10.3138/jvme.0216-040R

Hitchcott, P. K., Fastame, M. Ch., Ferrai, J., \& Penna, M. P. (2017). Psychological well-being in Italian families: An exploratory approach to the study of mental health across the adult life 
REVISTA DE LA UNIVERSIDAD DEL ZULIA. 3é época. Año $12 \mathrm{~N}^{\circ}$ 34, 2021

Yaroslava Z. Vasylkevych et al. /// Creativity and uncertainty tolerance as a resource... 585-603

DOI: http://dx.doi.org/10.46925//rdluz.34.32

Span in the Blue Zone. Europe's Journal of Psychology, 13(3), 112-122. https://doi.org/10.5964/ejop.v13i3.1416

Huang, D. M. (2006). Correlation study on reading anxiety and tolerance of ambiguity. Journal of Hubei Institute of Education, 23(11), 126-128.

Karwowski, M., \& Kaufman, J. C. (2017). The creative self: Effect of beliefs, self-efficacy, mindset, and identity. San Diego, CA: Academic Press.

Kaufman, J. C., \& Sternberg, R. J. (2019). The Cambridge handbook of creativity. New York: Cambridge University Press.

Kwan, L. Y.-Y., Leug, A. Y.-K., \& Liou, S. (2018). Culture, creativity, and innovation. Journal of Cross-Cultural Psychology, 2, 231-238. https://doi.org/10.1177/0022022117753306

Li, E. L. (2006). Gender differences on tolerance of ambiguity. Journal of Sanmenxia Polytechnic (Comprehensive Edition), 5(3), 65-67.

Lubart, T. (2010). Children's creative potential: an empirical study of measurement issues. Learning and Individual Differences, 20, 388-392. https://doi.org/10.1016/j.lindif.2010.02.006

Muñoz, O. (2019). Cultura, gestión pública, gerencia y sistema de relacionamiento. Revista Latinoamericana De Difusión Científica, 1 (1), 55-67. Recuperado a partir de http://www.difusioncientifica.info/index.php/difusioncientifica/article/view/6

Norton, R. W. (2002). Measurement of ambiguity tolerance. Journal of Personality Assessment, 39(6), 607-619. https://doi.org/10.1207/s15327752jpa3906_11

Pakhol, B. Ye. (2017). Subjective and psychological well-being: modern and classical approaches, models and factors. Ukrainian psychological journal, 1(3), 80-104. http://doi.org/10.17721/upj.2017.1(3).7

Paskov, M. (2017). Does employment status affect psychological well-being? UK Data Service. http://blog.ukdataservice.ac.uk/employment-and-psychological-wellbeing

Preiss, D. D. (2019). Recent advances in the psychology of creativity. Stadies in Psychology, 40, 491-496. http://doi.org/10.1080/02109395.2019.1679456

Rafferty, A. E., Jimmieson, N. L., \& Armenakis, A. A. (2013). Change readiness: A multilevel review. Journal of Management, 39(1), 110-135. https://doi.org/10.1177/0149206312457417

Ryff, C. (1995). The structure of psychological well-being revisited. Journal of Personality and Social Psychology, 69, 719-727. https://doi.org/10.1037/0022-3514.69.4.719

Wilson, J. M., Weiss, A., \& Shook, N. J. (2020). Mindfulness, self-compassion, and savouring: Factors that explain the relation between perceived social support and well-being. Personality and individual differences, 152, 1-9. https://doi.org/10.1016/j.paid.2019.109568 